\title{
Practice and Exploration of Graduate Joint Cultivation Base of Transportation Industry
}

\author{
Xinde Tang*, Yueqing Yang, Jin Liu, Zhan Qu \\ Department of Discipline and Graduate Education \\ Shandong Jiaotong University \\ Jinan, China \\ *X. D. Tang (xdtang8033@163.com)
}

\begin{abstract}
Aiming at the cultivation of high-level innovative, interdisciplinary, practice and exploration of professional degree graduate joint cultivation base in the area of transportation engineering have been conducted. Some questions were focused such as insufficient guarantee condition, loose training process, weak management, and low efficiency for the joint cultivation base construction, "two skins" for base and course, the separation of theory and practice, etc. Some strategies to solve these shortcomings were proposed combining our practice and exploration. It can be anticipated the realization of high-efficient practicing platform, internal power and intellectual support, and resources and environment security.
\end{abstract}

Keywords-graduate joint cultivation base; transportation industry; professional degree graduate education; practice

\section{INTRODUCTION}

It is the development direction of graduate education reform to carry out university-enterprise cooperation, improve cooperative innovation mechanism, and strengthen joint training base construction. In recent years, various universities have practiced and explored in the joint cultivation base construction for making full use of talent, technology, and environment advantages, providing good practice opportunities for graduate students. Meanwhile, it is of great significance for high-level and innovative talents cultivation. It has been proven that the graduate joint cultivation base is playing a positive role in making up for the practicing resources shortage, promoting enterprise technology progress, and improving graduate practice innovation ability [1]

However, during the construction process of graduate joint cultivation base, due to the unclear boundary of responsibilities, right, and benefit between universities-enterprises, insufficient guarantee conditions, loose training process, weak daily management, and poor performance, sustainable development exhibits underpowered and unsatisfactory training quality, which should be need to be addressed. At present, the education workers in universities have done a lot of research and exploration from the theoretical and practical level, and some achievement has been obtained.

X. D. T. thanks the financial support from Shandong Provincial Graduate Education Innovation Project of China (Grant No. SDYY15082 and 14080).

\section{Current Research Status}

A. To optimize the system, mechanism and the management model is the first and core issue of graduate joint cultivation base construction

Based on analyzing the necessity of constructing university-enterprise graduate cultivation base, in view of the unclear ownership, lack of funding, unsound organization, imperfect management system, low motivation od enterprise, the contradiction between graduate curriculum and enterprise, social demand, to establish base management committee, offering special courses to meet the enterprise needs, to develop cooperative security system, to improve the dual tutor management mechanism, and to establish fund safeguard and the intellectual property right sharing mechanism for promoting the healthy and sustainable development of graduate cultivation bases was proposed by Li's group [1].

Zheng et al. thought, by establishing a "linkage" base management model, making effective organization and management system, constructing a training mode of dual tutor system, jointly building scientific research innovation platform, the ability of graduate student innovation and engineering practice can be effectively improve [2]. Wen et al. investigated the base management model by improving the quality of graduate education and guaranteeing the main interests, and put forward the fabrication of "parallel interactive classroom and thesis" training system, the creation of a compound talent training environment, the establishment of "symbiosis" and "independent" management system, providing the graduate scientific research practice platform, playing a role of tutor team, introducing incentive mechanism and so on [3].

\section{B. To combine regional and industrial characteristics to} realize resource sharing is an important way to construct graduate joint cultivation base

Pan et al. proposed to intensify the cultivation of high-level talents, strengthen the graduate education to combine with science and technology, and promote the development of regional economy and society through resource sharing between enterprises, universities and research institutes. The construction system of graduate cultivation with universities as the main body, enterprises as the main force, the government as the main dominant was fabricated, in which various bodies exhibit positive interaction through the coordination of management, evaluation and guarantee system [4]. 
Xing et al. put forward the "four combinations" innovative cultivation model (scientific research and industry practice, basic research and engineering application, systematically learning theory and breaking traditional thinking, meeting the reality demand and tracking technology frontier). The sustainable and high-level research platforms were provided for graduate student innovation ability through the compaction university-enterprise cooperation mechanism [5].

\section{To construct the evaluation system of graduate joint training base is an important guide for the base construction}

Based on the perspective of education resource efficiency, Huang et al. constructed the evaluation index system from three aspects of the education input, process management, and output achievements [6].

Above research focused on the system, mechanism, management, resource, and evaluation of graduate joint training base, and suggested to stimulate vitality of joint training base and training function, to provide important support for high-level talents training by establishing a relatively complete organization and guarantee system. Research achievements of graduate joint training base construction has a certain guiding role, it is necessary to further expand and deepen the connotation and function of graduate joint training base with the diversification and specialization of high-level talent cultivation system.

\section{FOREIGN AND DOMESTIC MODELS}

Professional degree graduate education is an emerging cultivating model based on the practical needs of engineering, which is an important way to cultivate high-level talents in the field of professional field in accordance with economic and social development. In March 2009, the Chinese Ministry of Education issued "Opinions on full-time professional master degree graduate education", which plays an important role in professional degree graduate education reform and innovation. Graduate education is transferring from academic talents to applied talents. Paying attention to absorbing and use social resources, establishing joint training bases, and jointly training professional degree graduate student has been a tendency in China.

In recent years, with the expansion of the enrollment scale of professional degree graduate students, the status and role of graduate joint training base in education of professional degree graduate students are becoming more and more prominent. Experts and scholars have conducted many useful discussions on its operation mechanism and mode. In the case of foreign countries, Germany, the United States and Japan have developed graduate education. Among them, Germany is one of the world-class models, whose "Apprentice" mode using "tutorial system" as the core, emphasizing on discussion and experiment segments, and practice training [7]. The collaborative style of master's degree program in the United States is jointly developed by the "Steering Group", focusing on the cooperation with industrial and commercial enterprises [8]. In Japan, there exists an integrated model of industry, academy, and research, emphasizing on "industrial laboratory". Above three graduate education modes have different features, but their common characteristic is to pay attention to the students' ability of practical scientific research and practical application, or directly to involve in the scientific research practice and combine with the demand of industrial enterprise [10]. These advanced experience is worth learning from the new models. Zhou analyzed the common characteristics of these countries, which pay attention to student's actual scientific research ability. He put forward the training mode of "universities+joint base", paying attention to social practice, joint training base, and dual-tutor system [11]. Combining with the characteristics of engineering colleges, Geng et al. analyzed the problems existing in the professional master cultivation and four most common way for the cooperation between universities and enterprises: The universities employ the tutors from the enterprises; The enterprises provide funding for projects; The graduate class are established by universityenterprise cooperation; Scientific research bases are built by university-enterprise cooperation. He pointed out that establishing university-enterprise joint graduate training base is the best way to professional degree applied talents [12].

For the requirements of training professional degree graduate students, Gong et al. analyzed the current problems of professional degree graduate education base, and put forward the strategy of creation and maintenance, including to explore various styles for base construction and to build management mechanism etc. [13]. For meeting the demand of industry talents, promoting the development of water conservancy, innovating modes of graduate education, and promoting the development of professional degree graduate education, Shi et al. thought that the graduate training base construction need to be carefully planning and to establish system, to sign agreements and to establish organization, to select tutors and to organize training, to release guide and to enter base; to follow up feedback and to perfectly match. To solve the problems of the construction and management of graduate training base, we need to strengthen management and further improve the management level of graduate training base. We should pay much attention to the ideological and political education for the graduate students. A professional degree thesis evaluation system with strict control and scientific standard and a link mechanism between professional degree and vocational qualification certificate should be established [14]. Chen et al. summarized three patterns of full-time engineering master graduate training base construction: the domain pattern relying on the large enterprises, regional pattern relying on professional town, and industry pattern relying on the industry associations [15]. "Three Across" training mode was explored for graduate education in Northeast Petroleum University, in which the innovation practice bases were used as the carrier. By strengthening the graduate students' scientific research, practice and innovation ability as the key point, relying on the across-region, across-field and across-time (phase), the quality of the full-time professional degree graduate education was steadily improved [16].

From the existing literature, it can be found that the system, mechanism, and management model on the graduate joint training base construction are mostly limited to theoretical level, and the combination with the characteristics of industry or area is less. As for how to evaluate joint training base, there 
is no uniform standard. In particular, the construction of graduate joint training base suitable for professional degree graduate education should be carried out, operated, and evaluated effectively. The space of theoretical or practical exploration is very large.

\section{OUR STRATEGY}

Shandong Jiaotong University, as a typical university with transportation industry background, originally belonging to Chinese Ministry of Communications, was established in 1956. In 2011, it obtained the project entitled "service for national special demand"-a master degree graduate education qualifications. "Rooted from transportation, service for transportation" is the internal development source. How to take advantage of transportation industry resources, how to construct graduate joint training base, and how to service for training high-level talents, are the common topics for universities-enterprises of transportation industry. Since 2011, more than 20 graduate joint training base have been established, covering a number of areas and directions. However, widespread problems such as wasting resources, extensive management, and low efficiency seriously affected the normal action, which is not conducive to the cultivation of high-level personnel and must be reformed and improved.

In the 2014 national transportation conference, comprehensively deepening reform in the future, and focusing on accelerating the development of "Four Transportation" was proposed: comprehensive transportation, intelligent transportation, green transportation, and peaceful transportation. Among them, comprehensive transportation is the core, intelligent traffic is the key, the green transportation is the leader, and safe transportation is the foundation. "Four transportation" relate and complement each other, constituting the organic system for promoting the development of the transportation modernization. As a university with the background of transportation industry, it is supposed to be actively trained in the demands of "Four transportation", especially the cultivation of high-level talents to meet the needs of the transportation industry. Based on transportation sector graduate joint training base construction, by optimizing the system mechanism and management model, it is of great significance to realize the condition standardization, process normalization, management institutionalization, and operation normalization, the organic integration of theory and practice, further establishment of win-win cooperation.

For professional degree graduate education, joint training base construction is the foundation. Based on the analysis and evaluation of the existing bases, six bases are determined as the samples, which covered the six directions of the two fields (Transportation Engineering, and Ship and Ocean Engineering). Through practice and exploration, we strive to realize efficient operation and provide demonstration and experience for other bases, and provide reference for graduate joint training base construction in transportation industry.

To cultivate high-level innovative, compound and applied talents as the goal, graduate joint training bases have been constructed. Based on "service for national special demand", three problems have been focused as follows:
1) Insufficient guarantee condition, loose training process, weak management, poor performance, and low efficiency should be solved to realize condition standardization, process normalization, management institutionalization, and operation normalization. The efficient practice platforms could be provided for engineering master program;

2) The "two skins" between universities and enterprises should be solved to realize the integration of theory and practice, classroom and base. The transportation endogenous motivation and intellectual support could be provided for engineering master education;

3) The problem concerning lack of contact with industry and insufficient resources should be solved to realize win-win cooperation based on traffic and closely linking. Resource and environment security could be provided for engineering master education.

Graduate joint training base construction is an important carrier of professional degree graduate education and an important platform for cultivating master's practical ability. Its significance lies in focusing on the common problems in the base construction. It can accumulate experience effectively and improve the overall level of base construction, and realize the organic integration of classroom and base. In addition, it can make professional degree graduate education to adapt and meet the demand of high-level talents for transportation industry development, establishing a win-win cooperation and longterm mechanism.

\section{CONCLUSIONS}

Based on the cultivation of high-level innovative and interdisciplinary, practice and exploration of professional degree graduate joint cultivation base in the area of transportation engineering have been conducted. Some problems including insufficient guarantee condition, loose training process, weak management, and low efficiency for the joint cultivation base construction, "two skins" for base and course, and the separation of theory and practice were discussed. Some constructive suggestions have been proposed. It can be anticipated the realization of high-efficient practicing platform, internal power and intellectual support, and resources and environment security.

\section{REFERENCES}

[1] H.Li, X. Liu, and H. Lu, "Research on the construction of innovation base for graduate training by cooperation of universities-enterprises," Journal of Lanzhou Education College, vol. 29 (5), pp. 61-62, 2013.

[2] J. Zheng and Q. Su, "Practice and reflection on the construction of joint training base for graduate students," Jiangsu High Education, vol. (6), pp. 90-91, 2011.

[3] Y. Wen and A. huang, "The management practice of establishing graduate joint training base," China Adult Education, vol. (18), pp. 2830, 2013.

[4] L. Pan, G. Chai, and X. Peng, "Research on the construction characteristics, system and strategy of graduate training base," Journal of Zhejiang University of Technology (Social Science Edition), vol. 11 (1), pp. 51-55, 2011

[5] S. Xing, G. Xiao, C. Peng, and J. Zeng, "The exploration practice of the development of graduate innovation cultivation base of university- 
enterprise cooperation," Journal of Higher Education Research, vol. 35 (4), pp. 107-108, 2014.

[6] Q. Huang, "Research on the evaluation system of graduate training basebased on the view of education resource utilization efficiency," China Adult Education, vol. (22), pp. 34-36, 2014.

[7] F. Xie, B. Wang, and H. Li, "The formation mechanism of graduate education in Germany and the United States," Science and Technology Research, vol. 24 (6), pp. 38-40, 2005.

[8] H. Zhu and C, Chen, "Graduate training model in American universities," Jiangsu High Education, vol. (3), pp. 143-146, 2009.

[9] X. Yang, "Analysis of education model in Germany, USA and Japan," China Metallurgy Education, vol. (5), pp. 76-79, 2006

[10] L. Shi and Y. Chen, "Comparison and discussion on the training methods of graduate education in domestic and abroad," Journal of Southeast University (Philosophical and Social Science Edition), vol. 12 (3), pp. 117-121, 2012.

[11] J. Zhou and Y. Lu, "Discussion on 'university + joint training base' graduate training mode," University Education, vol. (9), pp. 13-14, 2013.
[12] Y. Geng, Q. Wen, and D. Shan, "Establishment of joint graduate training base for university-enterprises to make advanced applications of professional degrees," Management Science, vol. (2), pp. 47, 2015.

[13] C. Gong, S. Wang, and L. Lu, "The practice base construction model for graduate student training," Education and Teaching, vol. (46), pp. 250251, 2013.

[14] H. Shi, "Study and practice of graduate training base construction," University Education, vol. (19), pp. 9-10, 2013.

[15] X. Chen, W. luo, W. Cao, and R. Ge, "Consideration and practice of cultivation base construction of full-time engineering graduate students," vol. (2), pp. 46-49, 2012.

[16] Z. Wang, Y. Gao, and C. Zhao, "Research on full-time degree programs based on innovative practice base," Education and Teaching, vol. (33), pp. 150-151, 2013. 